\title{
Is There an Optimal Strategic Oil Reserve for Each Country? A Study Based on the Game Theory
}

\author{
Junan Yang $^{1}$ and Rong-Gang Cong ${ }^{*}, 2,3$ \\ ${ }^{1}$ Hebei Professional College of Political Science and Law, Hebei, 050067, China \\ ${ }^{2}$ Department of Environmental Science, Aarhus University, Roskilde, 4000, Denmark \\ ${ }^{3}$ Centre for Environmental and Climate Research (CEC), Lund University, Lund S-22362, Sweden
}

\begin{abstract}
In generally, there is a phenomenon of "free rider" in the establishment of national oil reserves for different countries, which means that they have the tendency of underestimating the strategic oil reserves. This paper attempts to explain this phenomenon from the perspective of non-cooperative game theory. It also analyzes the establishment of strategic oil reserve among different countries based on the coalition game theory and presents the core solution for it. The results show that based on a certain constraint mechanism, it is feasible for different countries to establish their own suitable strategic oil reserves in theory and practice.
\end{abstract}

Keywords: Coalition game, cooperative strategic reserve, core solution, game theory.

\section{INTRODUCTION}

Strategic oil reserve is the oil reserves required for the national strategy, which aims to increase the reliability of national oil supply, stabilize oil prices, reduce the national macro-economic losses due to the oil crisis $[1,2]$. The US strategic petroleum reserve is the largest government-owned stockpile in the world, whose current volume is 695.9 million barrels of crude oil in 2013. In the European Union, the member countries must hold a strategic oil reserve which equals to 90 days daily consumption, according to the Council Directive 68/414/EEC. In Asia, Chinese government also began to establish the strategic reserve from 2007. It consists of a government-owned reserve and mandated commercial reserves. China aims to increase its strategic reserve to 90 days of supply by 2020 .

In the establishment of national oil reserves, there are two important issues in which one is a phenomenon of "free rider", that is countries without strategic reserves can benefit from the countries with strategic reserves [3,4]. When the oil supply is interrupted, the latter release the oil reserves and reduce their import demand for oil, which will decrease the oil price. The former can get revenue from the falling oil prices without oil reserves. Therefore, many countries have the tendency of underestimating the oil reserves. In the other word, it should be possible for mutual collaboration of managing strategic oil reserves among countries, contrast to managing reserves individually.

Hogan presented this problem and investigated the game between two countries based on a Stackelberg model [5]. Hubbard and Weiner investigated the spillover effects of one

*Address correspondence to this author at the Centre for Environmental and Climate Research (CEC), Lund University, Lund S-22362, Sweden;

Tel: +46 46 2228633; E-mail: cascong@126.com country with strategic oil reserve on other countries [6]. Devarajan and Weiner discussed how to release the strategic reserves in the disruption of oil when the behavior of one country can have some impact on the world oil price [7]. Therefore, whether there is a stable coalition where there is not free-riding tendency is the first issue needed to present.

The second issue is whether every country has its own best strategic oil reserve scale. In the game theory, the important thing is whether there is a unique value for every country's oil reserve and how to obtain it. However, current regulations usually set the same limit for all the countries, e.g. 90 days of consumption (or supply). The literature about the phenomenon of "free rider" is also relatively few and most literatures try to explain it from the qualitative perspective [8-10]. This paper is an attelmp to explain the two issues above based on a game model in theory.

\section{NON-COOPERATIVE GAME ANALYSIS OF STRATEGIC OIL RESERVES}

The game can be described as follows: there are $\mathrm{n}$ oilimported countries $(\mathrm{i}=1, \ldots, \mathrm{n})$. Their decision spaces are their strategic oil stocks, which are represented as $x_{i}$. If the strategic oil stocks are assumed as continuous variables, every country has infinite decisions. Let $a_{i}$ is the imported oil needed for every country. For simplicity, there are some assumptions as follows:

(1) It is a two-period game. At the first period, every country establishes its strategic oil reserve. At the second period, there is an oil interruption. Every country must release their reserves to partially meet their import needs. Therefore, the condition, $0 \leq x_{i} \leq a_{i}$, is always right. 
(2)

$\mathrm{D}$ is assumed as the total demand of oil market. In the interruption, $D=\sum_{i=1}^{n}\left(a_{i}-x_{i}\right), \mathrm{i}=1, \ldots, \mathrm{n}$. The market clearing price of oil is the function of demand. And the price increases as the demand increases. Price is linearly related to demand.

$P(D)=c+b \sum_{i=1}^{n}\left(a_{i}-x_{i}\right), c>0,0<b<1$

In the above equation, $\mathrm{c}$ is the oil price when the demand is zero. It is very similar to the cost price. B is the slope rate of price function.

The cost for country I in the interruption is :

$\pi_{i}=\left(a_{i}-x_{i}\right) *\left[c+\sum_{i=1}^{n}\left(a_{i}-x_{i}\right)\right]+d_{i} x_{i}$

In the equation above, $d_{i}$ is the oil price plus the storage cost for one period in the normal times. If the storage costs are the same for all of the countries then, $d_{i}=d$. The goals of every country is to choose a optimism oil stock, which can minimize the cost of interruption, as follows:

$\min _{x_{i}} \pi_{i}=\left(a_{i}-x_{i}\right) *\left[c+\sum_{i=1}^{n}\left(a_{i}-x_{i}\right)\right]+d x_{i}, \mathrm{i}=1, \ldots, \mathrm{n}$

According to the definition of Nash equilibrium, the decision variable, $x_{i}$, of country $i$ should meet the equilibrium condition, as follows:

$\frac{\partial \pi_{i}}{\partial x_{i}}=0 \mathrm{i}=1, \ldots, \mathrm{n}$

That is to say:

$-c-\sum_{i=1}^{n}\left(a_{i}-x_{i}\right)-\left(a_{i}-x_{i}\right)+d=0 \mathrm{i}=1, \ldots, \mathrm{n}$

The summation of $\mathrm{n}$ equations above is as follows if we define that $A=\sum_{i=1}^{n} a_{i} ; X=\sum_{i=1}^{n} x_{i}$

$n *(d-c)-(n+1) * A+(n+1) * X=0$

$X=A-\frac{n}{n+1} *(d-c)$

Take the equation (7) into equation (5), we can get:

$x_{i}^{*}=a_{i}-\frac{1}{n+1}(d-c) ; a_{i}-x_{i}^{*}=\frac{d-c}{n+1}$

The cost of country I is:

$\pi_{i}^{*}=a_{i} d-\frac{(c-d)^{2}}{(n+1)^{2}}$

Total stock of $\mathrm{n}$ countries is:
$X=A-\frac{n}{n+1}(d-c)$

The total cost is:

$\pi=A d-n * \frac{(c-d)^{2}}{(n+1)^{2}}$

If there is cooperation among countries, we can transform equation (3) as follows.

$\min _{X} \pi=(A-X) *[c+A-X]+d X$

We can conclude that:

$X^{\prime}=A-\frac{d-c}{2}, \pi^{\prime}=A d-\frac{(d-c)^{2}}{4}$

When $n \geq 2, X^{\prime}>X, \pi^{\prime}<\pi$

Therefore, there is the phenomenon of "free rider". Each country has the tendency to underestimate the oil reserve stock, while it actually increases its own costs. Infact, China has been doing something as a free rider until now who lets other countries (i.e. USA and Europe) to bear the huge cost of strategic oil reserve and assuming they would release their reserves to keep world price down in a crisis. Our model analyzed the reason behind the free-rider problem in keeping strategic oil reserve.

\section{THE ANALYSIS OF COALITION GAME OF STRATEGIC OIL RESERVE}

Since in the case of non-cooperation, each country has the tendency of "free rider". Is it possible to the establishment of cooperation between countries? IEA sets the minimum of 90 days net imports of oil for the strategic oil stock. Is it reasonable? In the case of cooperation among countries, should every country has its own strategic oil reserves? Next, the paper attempts to explain it from the perspective of coalition game theory.

We assume $N=M \bigcup M^{\prime}$ is the set of agents. $M=\{1, \ldots, m\}$, stands for the different cost losses when there is an oil interruption. The element $\mathrm{I}$ in the set $\mathrm{M}$ stands for a GDP loss of $a_{i} \cdot M^{\prime}=\{m+1, \ldots, 2 m\}$ stands for the oilimport countries with oil reserve. The element $\mathrm{j}$ of Set $M^{\prime}$ must cover a loss. The loss for country i is $b_{i j}=\pi_{j} S_{i j} . \pi_{j}$ is the marginal cost of oil reserve of country i. $S_{i j}$ is the stock period of country $j$. There is a coalition game in set $\mathrm{N}$. We can assume $\mathrm{V}$ as the eigen function of coalition game.

If there are $i \in M$ and $j \in M^{\prime}$ which have complementary relationships, we can get:

$V\{i, j\}= \begin{cases}a_{i}-b_{i j} & a_{i} \geq b_{i j} \\ 0 & a_{i}<b_{i j}\end{cases}$

For $s \subseteq M, \mathrm{~V}(\mathrm{~s})=0$, there is only loss of GDP and not any game in essence. For $s \subseteq M^{\prime}, \mathrm{V}(\mathrm{s})=0$, there is only investment and again not any game in essence. For others, 
$\mathrm{V}(\mathrm{s})$ is the minimum loss when there is some compensation. If we assume the investment is less than GDP losses and $i \in s \cap M$, the investment, $\mathrm{j}(\mathrm{i})$, cannot cover the GDP loss in total. $j(i) \in s \cap M^{\prime}, j(i) \in\{m+1, \ldots, 2 m\}$. The total loss of $\mathrm{s}, V(s)=\min \sum_{j \in s \cap M^{\prime}} C_{i j(i)}, C_{i j(i)}=a_{i}-b_{i j}$.

$$
C_{i(j) j}=b_{i j}-a_{i} \text {, So } V(N)=\min \sum_{i=1}^{m} C_{i j(i)}=\min \sum_{j=m+1}^{2 m} C_{i(j) j}
$$

We can define the coalition game as $\Gamma=<N, V>=<M \cup M^{\prime}, V=\min \sum>$.

In the coalition game, there is core solution. If $\mathrm{n}$ dimensional vector $\left(x_{1}, \ldots, x_{n}\right)$ can meet the condition:

$x_{i} \geq v(\{i\}), i=1, \ldots, n, \sum_{i=1}^{n} x_{i}=v(N)$

It can be defined as a distribution. All the $x_{i}$ can be included as a set, $X(\Gamma)$.

We define $C(\Gamma)=\{x \mid x \in X(\Gamma) ; v(S)-x(S) \geq 0, S \subset N\}$ as the core solution of N. From the perspective of economics, the core solution is a distribution where the coalition of agents is better for every agent than the noncooperation. Our goal is to examine whether there is a core solution in the coalition game above. If any, how can we calculate it?

A replacement square is introduced:

$$
P=\left(P_{i j}\right)_{m^{*} m}=\left(\begin{array}{ccc}
p_{1, m+1} & \cdots & p_{1,2 m} \\
p_{2, m+1} & \cdots & p_{2,2 m} \\
\cdots & \cdots & \cdots \\
p_{m, m+1} & \cdots & p_{m, 2 m}
\end{array}\right)
$$

$V(N)=\min \sum_{i=1}^{m} C_{i j(i)}=\min \sum_{i=1}^{m} \sum_{j=m+1}^{2 m} p_{i j} C_{i j}$

Every GDP loss must be covered by one country. We show it in the replacement square as:

$$
\begin{array}{cl}
\text { s.t. } & \sum_{i=1}^{m} p_{i j}=1 \quad j=m+1, \ldots, 2 m \\
\sum_{i=m+1}^{2 m} p_{i j}=1 \quad i=1, \ldots ., m \\
p_{i j} \in\{0,1\}, p_{i j} \text { is } 0 \text { or } 1
\end{array}
$$

If the constraint is dropped, a relaxed linear program can be shown as follows:

$$
V(N)=\min z=\sum_{i=1}^{m} C_{i j(i)}=\min z=\sum_{i=1}^{m} \sum_{j=m+1}^{2 m} q_{i j} C_{i j}
$$

$$
\begin{aligned}
& \text { s.t. } \sum_{j=1}^{m} q_{i j}=1 \quad j=m+1, \ldots, 2 m \\
& \sum_{i=m+1}^{2 m} q_{i j}=1 \quad i=1, \ldots ., m \\
& q_{i j} \geq 0
\end{aligned}
$$

The economic meanings of the relaxed program are in the perspective of probability, GDP losses are corresponding to the countries with strategic oil reserves.

For the equation above, if we assume that $S=\{(i, j)\}$, $\mathrm{i}=1, \ldots, \quad \mathrm{m} ; \mathrm{j}=\mathrm{m}+1, \ldots, 2 \mathrm{~m}, \quad \mathrm{R}=\{(\mathrm{i}, \mathrm{j}), \mathrm{i}=1, . ., \mathrm{m} ; \mathrm{j}=\mathrm{m}+1, \ldots, 2 \mathrm{~m}\}$, the equation above can be shown as $y(S)=q_{i j}, v(S)=c_{i j}$. The relaxed program can be shown as follows:

$$
\begin{aligned}
& \min z=\sum_{S \subseteq R} y_{S} v(S) \\
& \text { s.t. } \sum_{\substack{S \subseteq R \\
i \in S}} y_{S}=1, i=1, \ldots, m \\
& \quad \sum_{\substack{S \subseteq R \\
j \in S}} y_{S}=1, j=m+1, \ldots, 2 m \\
& y_{S} \geq 0, \forall S \subseteq R
\end{aligned}
$$

$\mathrm{S}$ is defined as the balance set of $\langle\mathrm{N}, \mathrm{v}\rangle$. $\left(q_{i j}\right)$ is the balance vector.

According to the duality theory, the dual linear program can be shown as follows:

$$
\begin{aligned}
& \max w=\sum_{i=1}^{m} y_{i}+\sum_{j=m+1}^{2 m} \partial_{j} \\
& \text { s.t. } y_{i}+\partial_{j} \leq C_{i j} \quad i=1, \ldots, m ; j=m+1, \ldots, 2 m \\
& y_{i}, \partial_{j} \text { are free variables }
\end{aligned}
$$

Because the constraint set is a finite set, there are feasible solutions for LP and DLP above. The duality theory holds, that is:

$\max w=\sum_{i=1}^{m} y_{i}^{*}+\sum_{j=m+1}^{2 m} \partial_{j}^{*}=\min z=v(N)$

$\sum_{i=1}^{m} \sum_{j=m+1}^{2 m} q_{i j} C_{i j} \geq v(N)$

$\sum_{S \subseteq R} y_{S} v(S) \geq v(N)$

Therefore, $<\mathrm{N}, \mathrm{v}\rangle$ is the balance game. According to the theory of Bondareva-Shapley, its core solution is $C(v) \neq \varnothing$.

$$
\left.\left\{\sum_{(\mathrm{i}, \mathrm{j}) \in \mathrm{S}} x_{i j}=y_{i}^{*}+\partial_{j}^{*}\right) \mid y_{i j}=1\right\} \leq \sum_{(i, j) \in S} C_{i j}, \sum x_{i j}=v(N)
$$

Therefore, $x_{i j}$ is the core solution of $C(v)$.

Our results prove that each country should have its own specific reserve size, which could depend on a number of 
factors, e.g. the economic growth rate, oil price, alternatives to oil (e.g. renewable energy policy), etc $[11,12]$. The uniform lower bound for strategic oil reserve is not efficient in theory.

\section{CONCLUSION}

The establishment of national strategic oil reserves is a process of game. This paper attempts to do a game analysis of different countries' oil reserves in the conditions of noncooperation and cooperation. The results show that compared with cooperation condition, in the condition of non-cooperation, the oil reserves of countries are less. The countries want to minimize their costs, however it is not a pareto optimum quantity for them. Based on the coalition model, we can derive the necessary conditions for the existence of coalition, that is, the core solution, which means that by some international negotiations, countries can build their own best strategic oil reserves to achieve the pareto improvement.

China is the second oil consuming and oil-imported country. Not only for the economic development of China, but also taking into account the impact of world oil market, the establishment of strategic oil reserves is a very important task. Since the "Tenth five-year plan", Zhenhai strategic oil reserve base has been put into use. In 2010, the strategic oil reserve of China was equivalent to 30 days of net oil imports. If China wants to join the IEA organization, it must meet the minimum 90 days oil reserves. As for oil, which is an important international good, the cooperation among countries is essential. But each country should have an optimum oil reserves according to their economic development. This paper attempts to give some theoretical support in this regard. In the future, we will try to employ empirical data to study the optimal strategic oil reserve for specific countries considering the oil price shocks and economic development $[13,14]$.

\section{CONFLICT OF INTEREST}

The authors confirm that this article content has no conflict of interest.

\section{ACKNOWLEDGEMENTS}

Declared none.

\section{REFERENCES}

[1] Teisberg, T.J. A dynamic programming model of the US strategic petroleum reserve. Bell. J. Econ., 1981, 12(2), 526-546.

[2] Pegg, S. Social responsibility and resource extraction: Are Chinese oil companies different? Res. Policy., 2012, 37(2), 160-167.

[3] Murphy, F.H.; Toman, M.A.; Weiss, H.J. A stochastic dynamic Nash game analysis of policies for managing the strategic petroleum reserves of consuming nations. Manag. Sci., 1987, 33(4) 484-499.

[4] Samouilidis, J.; Magirou, V.F. On the optimal level of a small country's strategic petroleum reserve. Eur. J. Oper. Res., 1985, 20(2), 190-197.

[5] Hogan, W.W. Oil stockpiling: Help thy neighbor. Energ. J., 1983 4(3), 49-71.

[6] Hubbard, R.G.; Weiner, R.J. Oil supply shocks and international policy coordination. Eur. Econ. Rev., 1986, 30(1), 91-106.

[7] Devarajan, S. ; Weiner R.J., Dynamic policy coordination: Stockpiling for energy security. J. Environ. Econ. Manage., 1989, 16(1), 9-22.

[8] Cong, R.-G.; Smith, H.G.; Olsson, O.; Brady, M. Managing ecosystem services for agriculture: Will landscape-scale management pay? Ecol. Econ., 2014, 99, 53-62.

[9] Oren, S.S.; Wan, S.H. Optimal strategic petroleum reserve policies a steady state analysis. Manag. Sci., 1986, 32(1), 14-29.

[10] Murphy, F.H.; Toman, M.A. ; Weiss, H.J. A dynamic Nash game model of oil market disruption and strategic stockpiling. Operat. Res., 1989, 37(6), 958-971.

[11] Wei, Y.-M., Wua, G.; Fana, Y.; Liua, L.-C. Empirical analysis of optimal strategic petroleum reserve in China. Energ. Econ., 2008, 30(2), 290-302.

[12] Saif, G.S. Assessment of the relationship between oil prices and US oil stocks. Energy Policy, 2006, 34(17), 3327-3333.

[13] Cong, R.-G.; Wei, Y.M.; Jiao, J.-L.; Fan, Y. Relationships between oil price shocks and stock market: An empirical analysis from China. Energy Policy, 2008, 36(9) 3544-3553.

[14] Cong, R.-G.; Shen, S. Relationships among Energy Price Shocks, Stock Market, and the Macroeconomy: Evidence from China. The Scientific World J., 2013, 2013 [Epub a head of print].

This is an open access article licensed under the terms of the Creative Commons Attribution Non-Commercial License (http://creativecommons.org/licenses/by-nc/3.0/) which permits unrestricted, non-commercial use, distribution and reproduction in any medium, provided the work is properly cited. 